\section{Applying the ecosystem services concept to poverty alleviation: the need to disaggregate human well-being}

\author{
TIM DAW ${ }^{1,2 *}$, KATRINA BROWN ${ }^{1}$, SERGIO ROSENDO ${ }^{1,3}$ AND \\ ROBERT POMEROY \\ ${ }^{1}$ School of International Development, University of East Anglia, Normich NR4 7TF, UK, ${ }^{2}$ Stockholm Resilience \\ Centre, Stockholm University, SE-106 91 Stockholm, Sweden, ${ }^{3}$ e-GEO, Faculdade de Ciências Sociais e \\ Humanas, FCSH, Universidade Nova de Lisboa, Avenida de Berna, 26-C, 1069-061 Lisbon, Portugal, and \\ ${ }^{4}$ Department of Agricultural and Resource Economics/Connecticut Sea Grant, University of Connecticut, Groton, \\ Connecticut, USA
}

Date submitted: 8 December 2010; Date accepted: 30 August 2011
THEMATIC SECTION

Payments for Ecosystem Services in Conservation: Performance and Prospects

\section{SUMMARY}

The concept of ecosystem services (ES), the benefits humans derive from ecosystems, is increasingly applied to environmental conservation, human wellbeing and poverty alleviation, and to inform the development of interventions. Payments for ecosystem services (PES) implicitly recognize the unequal distribution of the costs and benefits of maintaining ES, through monetary compensation from 'winners' to 'losers'. Some research into PES has examined how such schemes affect poverty, while other literature addresses trade-offs between different ES. However, much evolving ES literature adopts an aggregated perspective of humans and their well-being, which can disregard critical issues for poverty alleviation. This paper identifies four issues with examples from coastal ES in developing countries. First, different groups derive well-being benefits from different ES, creating winners and losers as ES, change. Second, dynamic mechanisms of access determine who can benefit. Third, individuals' contexts and needs determine how ES contribute to well-being. Fourth, aggregated analyses may neglect crucial poverty alleviation mechanisms such as cash-based livelihoods. To inform the development of ES interventions that contribute to poverty alleviation, disaggregated analysis is needed that focuses on who derives which benefits from ecosystems, and how such benefits contribute to the well-being of the poor. These issues present challenges in data availability and selection of how and at which scales to disaggregate. Disaggregation can be applied spatially, but should also include social groupings, such as gender, age and ethnicity, and is most important where inequality is greatest. Existing tools, such as stakeholder analysis and equity weights, can improve the relevance of ES research to poverty alleviation.

\footnotetext{
*Correspondence: Dr Tim Daw e-mail : t.daw@uea.ac.uk
}

Keymords: benefit distribution, coastal tourism, ecosystem services valuation, equity weighting, ESPA, fisheries, Millennium Ecosystem Assessment, payments for ecosystem services, trade-offs

\section{INTRODUCTION}

The current 'explosion of interest' (Perrings 2006) in ecosystem services (ES) and payments for ecosystem (or environmental) services (PES) partly stems from the Millennium Ecosystem Assessment (MA 2005), which developed and promoted a widely applied conceptual framework (MA 2003) based on a definition of ES as '... the benefits people obtain from ecosystems' (MA 2005, p. v). The ES concept originated as a metaphor to illustrate the reliance of humans and society on the biosphere (Daily 1997; Norgaard 2010), and is now applied to understand how options for ecosystem conservation, use and modification affect human well-being in specific cases through cost-benefit analysis, landscape planning, multi-criteria analysis and public policy (Fisher et al. 2009). The concept is also increasingly put into practice through PES, which aim to incentivize the maintenance of ES through transactions between actors with different agency, interests and willingness to pay for particular ES.

The ES literature draws on disciplines including economics, ecology, conservation and development and social policy, and has evolved into a number of related, but somewhat parallel strands, including theoretical development of the ES concept (see for example MA 2003), research on the generation and use of specific ES (Ronnback et al. 2007), monitoring and measurement of ES over time or space (Nelson et al. 2009), valuation (Bateman et al. 2011) and accounting (Boyd \& Banzaf 2007), applications and studies of PES schemes, both in theory (Wunder 2008) and practice (Wunder et al. 2008).

The MA, with an explicit focus on 'human well-being and poverty alleviation', highlighted the importance of ES for the well-being of poorer members of global society, and the relevance of the ES concept to contentious challenges of conservation, development and poverty alleviation (Adams 
et al. 2004). Recent scientific and policy initiatives have directly applied ES to poverty alleviation (for example see www.espa.ac.uk; TEEB [The Economics of Ecosystems and Biodiversity] 2010; WRI [World Resource Institute] et al. 2007), and emphasized their potential for alleviating poverty (FAO [United Nations Food and Agriculture Organization] 2007; WRI et al. 2008), while many government-led PES schemes have explicit or implicit poverty alleviation goals (Wunder et al. 2008).

In this paper, we critically examine the ES concept, as outlined by the MA and subsequent research, and how it may be applied to aid poverty alleviation and thus inform the design and implementation of pro-poor interventions, including PES. We use 'poverty alleviation' to include both 'poverty reduction', in which people are lifted out of poverty, and 'poverty prevention' in which ES contribute to maintaining people's well-being by meeting their immediate needs (Béné et al. 2010). We define poverty as lack of well-being, broadly understood, and focus on the relationship between ES and the well-being of the poorest in society. Our commentary is informed by a collaborative multiscale 'situation assessment' of marine and coastal ecosystem services (Brown et al. 2008) and illustrated by coastal examples from developing countries.

In searching for outcomes that achieve both environmental conservation and poverty alleviation (Bulte et al. 2008), some PES scholars have examined the impacts of PES on the poor. These studies generally conclude that different poor groups may benefit from PES, but that schemes cannot be optimized for both conservation and poverty alleviation (Wunder 2008; Zilberman et al. 2008). This literature is necessarily limited to ES that have been the subject of PES schemes, whereas a wider range of ES and contexts are important for the well-being of the poor. Meanwhile, other branches of the ES literature, while referring to poverty alleviation, often have limited relevance to poverty owing to their aggregated perspective of human well-being.

The relationship between ES and human well-being can be conceptualized in various ways. The initial insight from early ES literature (Daily 1997) and the MA is that ES contribute significantly to human well-being (Fig $1 a$ ). Changes in ES will have direct impacts on well-being, such that increasing ES may lead to poverty reduction and maintaining ES may lead to poverty prevention. The MA also emphasized that different ES contribute to different aspects of human wellbeing (for example material, health and security; Fig $1 b$; MA 2005, p. vi). Since the MA, several authors have also emphasized the existence of trade-offs between different ES, such that increases in one ES may lead, due to social-ecological dynamics, to declines in other ES (Fig 1c; Rodriguez et al. 2006; Carpenter et al. 2009). However the aggregate measures of ES in this research does not elucidate how the wellbeing of particular people is altered by such trade-offs. By 'aggregation', we mean the consideration of benefits to all 'humanity' (see Fig. 1a) without explicit recognition of distributional patterns of benefits between groups defined, for example, by geographical area, socioeconomic status, gender, a


Figure 1 Conceptualizations of ES and human well-being (WB) that do not disaggregate human well-being (i.e. the beneficiaries). Hypothetical increases in ES and well-being are indicated by bold boxes. (a) Simplistic aggregated view of well-being and ES, which leads to assumptions that increases in ES will lead to increases in well-being. (b) Elements of human well-being are disaggregated, recognizing that different ES may contribute to different elements of well-being. (c) ES are disaggregated to explore trade-offs between them.

ethnicity or time (in terms of current and future generations). Aggregation implicitly occurs when 'the benefits to humanwell being' are considered, measured or valued without explicit reference to different groups of humans who unevenly share the different benefits and costs of ES. It corresponds to what the MA (2003) referred to as 'social analysis', 'from the perspective of society as a whole', rather than 'private analysis' from the perspective of individual groups within society. We propose that any attempt to consider ES contributions to well-being without consideration of subgroups, explicitly or implicitly, results in aggregation of human well-being and is limited in its ability to inform about poverty alleviation. By definition, aggregate measures of ES flows, are poor indicators of the ES contribution to poverty alleviation of individuals, in the same way that national aggregate indices of wealth (such as gross domestic product [GDP]) hide wide variations in the wealth and fortunes of the poorest members of society (Ravallion 2001). This aggregation problem is more complex for ES, due to the existence of ES trade-offs, and the complex relationship between ES and the well-being of individual humans.

In this paper, we identify four critical issues concerning how ES relate to poverty alleviation that are overlooked or obscured by aggregated analysis. First, while aggregated analysis can identify trade-offs between different ES, it can overlook winners and losers in terms of who derives well-being benefits from which ES. Second this type of analysis also overlooks the dynamic mechanisms of access to ES that determine how ES contribute to the poor's well-being. Third, it overlooks individual circumstances and needs that determine the ES contribution to wellbeing. Fourth, aggregated analysis can lead to inappropriate conceptualizations and categorizations of ES and benefits, which may neglect crucial PA mechanisms such as ES-based cash and employment, and may affect understandings of the 
poverty implications of ES. We conclude by suggesting how disaggregation might be conducted in practice to improve the poverty-relevance of ES research and inform the poverty implications of PES, environmental management or other ES interventions.

\section{ISSUE 1. WINNERS AND LOSERS FROM ES TRADE-OFFS}

Various authors have drawn attention to the way in which ecosystem change leads to ES trade-offs between some types of ES (Rodriguez et al. 2006), while others are 'bundled' together (Raudsepp-Hearne et al. 2010a). Some progress has been made in documenting trade-offs in specific systems (Cheung \& Sumaila 2008; Nelson et al. 2009), but many attempts to model and quantify ES do not disaggregate the beneficiaries of those ES, thus ignoring the distribution of benefits between groups and individuals in society.

As discussed in the following sections, different individuals and groups benefit from, and rely on, different ES to different extents because of access mechanisms and individual contexts. For example, coastal Kenyan villagers use a wide range of ES from mangrove forests, but individual villagers perceived different ES according to their home village, gender and livelihood (Ronnback et al. 2007). As a result, each change in the 'bundles' of ES from an ecosystem will create winners and losers. Thus, trade-offs between different ES (as highlighted by Rodriguez et al. 2006) also lead to trade-offs between the well-being of different people (either between or within communities; Fig. 2a). Many examples exist that illustrate such trade-offs. In Kenya, the establishment of a marine protected area reduced the overall number of fishers in the area who benefited from fisheries (McClanahan \& KaundaArara 1996), while likely improving opportunities for tourism revenue. Some fishers lost their livelihoods, while others who had skills and opportunities to benefit from tourism improved their well-being through new employment opportunities.

PES attempts to explicitly address these trade-offs by allowing 'losers' to be compensated by 'winners', thus (theoretically) creating incentives for ES maintenance and more socially optimal outcomes. Wunder (2008) suggested further disaggregation to distinguish different poor groups based on their functional relationship to PES schemes (such as users, sellers and non-participants) and also suggested detailed disaggregation for targeting PES where poverty alleviation is the main goal. So while the PES literature has directed some focus towards winners and losers, other branches of the ES literature have yet to fully engage with the issue. Most attempts to model and quantify ES do not disaggregate beneficiaries, thus ignoring the distribution of benefits between groups and individuals in society. Other studies disaggregate between very broad groups of beneficiaries such as 'private interests' versus 'net social benefits' (Polasky et al. 2010) or broadly between stakeholders at different scales (Hein et al. 2006).

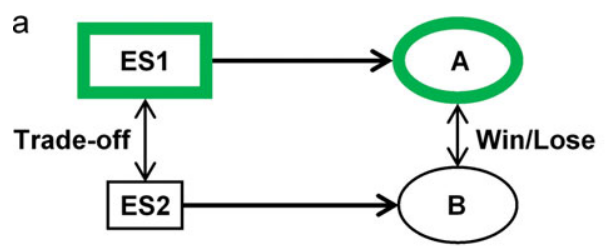

b
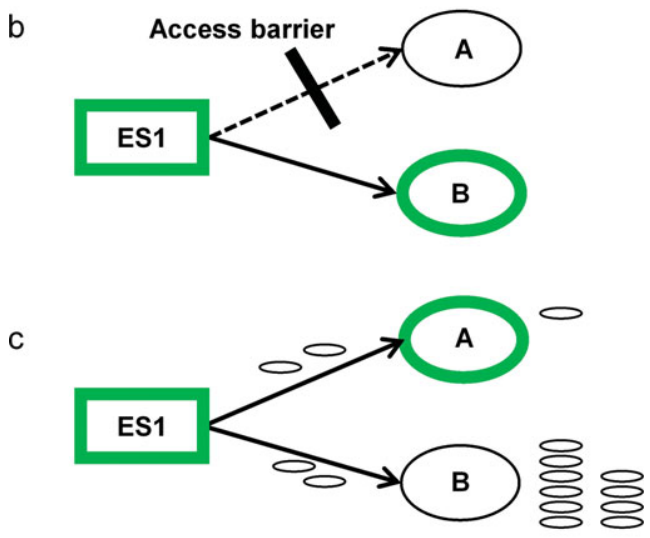

d

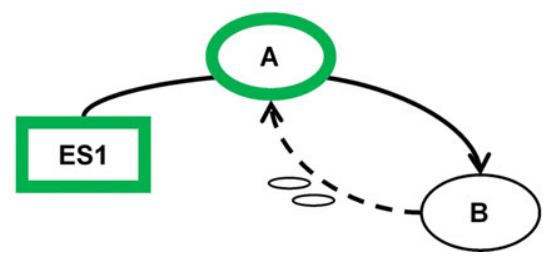

Figure 2 Aspects of ES and human well-being relevant to poverty alleviation that are highlighted by disaggregating human beneficiaries of ES. Each scenario shows an increase in the flow of an ES (highlighted boxes) and the differential impacts on two potential beneficiaries (A and B). (a) Trade-offs between different ES lead to winners and losers depending on who is placed to benefit from which ES. (b) Access mechanisms determine the well-being impacts of changes in ES. Increases in ES1 are captured by B but are not available to A. (c) Contribution of ES to well-being depends on the 'well-being-context' (in this case wealth) and needs of each beneficiary. Increasing ES1 contributes more to the well-being of A than $\mathrm{B}$ due to the importance of benefits relative to existing wealth or other livelihood opportunities. (d) Well-being contributions of ES1 to A results not from direct 'consumption' of ES1, but from the desire and willingness to pay of B to consume ES1.

In order to contribute to poverty alleviation, ES interventions should be informed by explicit consideration of the beneficiaries of ES bundles, now and under different future scenarios. Approaches to documenting trade-offs in ES (see Cheung \& Sumaila 2008; Polasky et al. 2010) could be made relevant to poverty alleviation by linking them to stakeholder analysis of the poor stakeholders who have access to, and reliance on benefits of each ES. Different ES have beneficiaries at different scales (Hein et al. 2006) and many recent ES assessments have been conducted within a spatially explicit framework (Nelson et al. 2010; Bateman et al. 2011). This offers some possibilities to identify winners 
and losers where these are spatially segregated. However, disaggregation of socioeconomic groupings within scales, for example by wealth, ethnicity, gender or livelihood groupings, may also be necessary to uncover losses otherwise hidden from analysis. Disaggregation to an appropriate level is necessary to address the issues of access and context described in the next sections.

\section{ISSUE 2. ACCESS MECHANISMS}

Conceptualization of ES and human well-being that aggregate humanity (Fig. 1a) lead to the assumption that improving or safeguarding the flow of ES will contribute to well-being and poverty alleviation. This is clearly an oversimplification (Butler \& Oluoch-Kosura 2006) and has been shown not to hold even at global scales (Dietz et al. 2009; Raudsepp-Hearne et al. 2010b). The degree to which any individual benefits from ecosystems depends on a complex range of mechanisms of access including social relationships, institutions, capabilities, rights and various capitals. This applies both to traditional resource use (Ribot \& Peluso 2003), as well as evolving mechanisms of PES (Pagiola et al. 2005; Zilberman et al. 2008). Increasing flows of an ES thus may have little effect on the well-being of the poor if they do not have access mechanisms to benefit from it (Fig. 2b). Conversely, the poor's well-being may change as a result of changes in access, regardless of changes in ecosystem functions. In Tanzania, connecting the octopus fishery to international markets increased the price available to fishers (so increased aggregate total benefits of the ES), but this led to the displacement of women, who traditionally had exclusive access to the fishery, by men attracted by the higher prices (Porter et al. 2008). Thus a change in the access institutions to this ES led to a direct trade-off between the well-being of two groups. Although the net value of the ES benefits and the well-being of male fishers were enhanced by new economic opportunities, this was at the expense of already-marginalized poor women.

The text of the MA framework referred to the importance of access: 'For poor people, the greatest gains in well-being will occur through more equitable and secure access to ecosystem services [rather than increases in ES per se]' (MA 2003 , p. 72), but aggregate approaches cannot capture the complex access mechanisms highlighted by Ribot and Peluso (2003).

\section{ISSUE 3. INDIVIDUAL CONTEXTS AND THE CONTRIBUTION OF ECOSYSTEM SERVICES TO WELL-BEING}

An aggregated evaluation of ES is particularly inadequate for understanding poverty defined as a multidimensional and dynamic concept (Alkire 2002). The MA conceptual framework emphasizes that ' $[\mathrm{h}]$ ow well-being and ill-being. . . are expressed and experienced is context- and situation- dependent, reflecting local social and personal factors' (MA 2003 , p. 71), with the implication that ES contributions to well-being, and by extension to poverty alleviation, can only be understood by taking account of the perspectives and circumstances of ES beneficiaries themselves. This 'well-being context' varies considerably between different individuals and groups, resulting in the same ES having different effects on the well-being of different beneficiaries (Fig. 2c). For example, fisheries may contribute to a sense of identity and job satisfaction to some individuals (Pollnac et al. 2001), according to their individual personalities (Pollnac \& Poggie 2008). Meanwhile, the contribution of regulating services to maintaining well-being (that is poverty prevention) depends on the exposure and sensitivity of individuals to environmental extremes, and their existing adaptive capacities (Adger et al. 2005).

In general, poor people have been shown to be more reliant on ES owing to the importance of natural-resourcebased livelihoods and their vulnerability to natural hazards (TEEB 2010). Women fishmongers on the Kenyan coast provide a good example of a poor ES-dependent group. They tend to have low socioeconomic status, and limited education, capital or opportunities (Matsue 2009). The access of these women to even small quantities of lowvalue fish therefore makes a disproportionately significant contribution to their well-being compared to wealthier groups with more alternatives. Likewise, fishers from poorer households are less likely to change to other occupations than those from wealthier households (Cinner et al. 2009) making them more vulnerable to declines in fisheries productivity.

ES benefits in terms of earnings can be valued easily using market prices, but the well-being contribution of cash income depends on the beneficiary's situation. Utilitarian economics has long recognized that the marginal utility of income decreases as income increases (Dasgupta 2001) so that any given level of financial benefit will have a greater wellbeing impact on a poor individual than a wealthier individual (Fig. 2c). Disaggregated ES assessments could use 'equity weights' to account for this (Pearce 2003) and express the greater well-being impact of ES that accrue to poorer beneficiaries. When calculated at aggregate national levels, equity weights have been shown to make a considerable difference to the understanding of welfare impacts of environmental changes (Srinivasan et al. 2008), and they are likely to have greater impacts when applied at sub-national scales (Baer 2009). Despite this, equity weights are not frequently used, have not been widely applied in ES valuation studies and remain controversial amongst some economists. An argument against the use of equity weights and for aggregate analysis in cost-benefit analysis is the view that total rents from a resource should be maximized, and subsequently contribute to poverty alleviation through redistributive taxes, or trickle-down effects in the economy (Johansson-Stenman 2005). However, this perspective is not appropriate when considering the ES contribution to the well-being of the poor, 
Figure 3 Benefits from three different coastal ES in East Africa which contribute to the well-being of local poor (in red): ( $a$ ) bivalves harvested for subsistence consumption and $(b)$ sea cucumber harvested for international trade contribute in entirely different ways, but are both categorized as provisioning services (food) whereas $(c)$ international tourism is categorized as a cultural service, although it basically provides income in the same way as $(b)$.
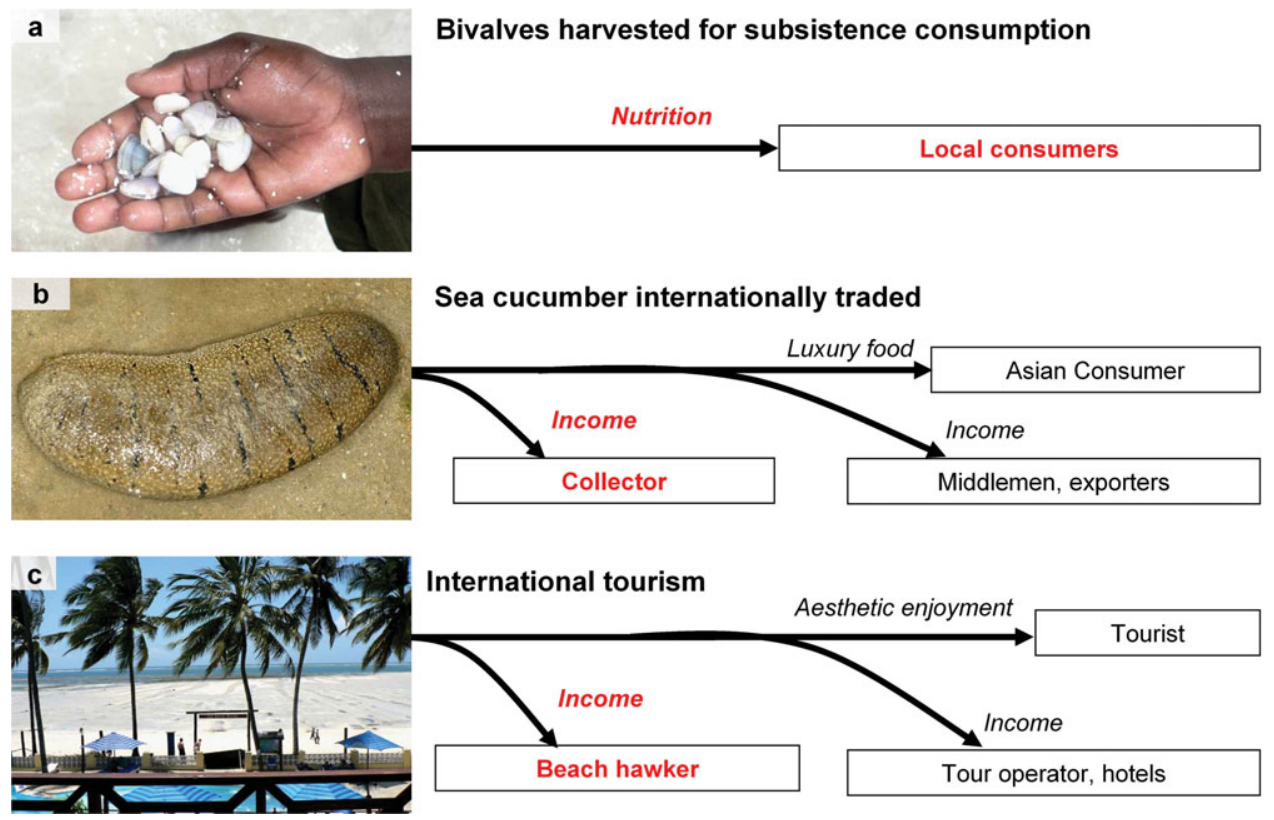

given the persistent exclusion of the poor from broader wealth generation (Landell-Mills \& Porras 2002), the non-use value of many ES, the lack of structured taxable markets for others and the ineffectiveness of institutions redistributing wealth in many developing countries. Furthermore PES may suffer from elite capture or corruption, thereby excluding the poor from benefits or exacerbating inequality (Kosoy \& Corbera 2010) The use of equity weightings or similar techniques to disaggregated assessments of ES benefits has recently been suggested in ES valuation literature (Balmford et al. 2011; Bateman et al. 2011) but we are unaware of their explicit use in any ES studies to date. Complex decisions around the appropriate values of equity weights are one disincentive to applying them, but valuation or cost-benefit studies that do not use equity weights implicitly employ a weight of unity, assuming in effect that US\$ 1 to a wealthy stakeholder has the equivalent welfare impact as US\$ 1 to a poor stakeholder (Pearce 2003).

\section{ISSUE 4. CONCEPTUALIZATION AND CATEGORIZATION OF ECOSYSTEM SERVICES AND BENEFITS}

The MA definition of ES as 'benefits that humans obtain from ecosystems' was broader than previous more 'ecological' definitions (see Daily 1997), and has been critiqued as overly generic (Boyd \& Banzhaf 2007) and inadequate for valuation applications (Fisher \& Turner 2008). We find that such a broad concept of $\mathrm{ES}$ is also inadequate for understanding poverty alleviation, with limited elucidation of how individuals benefit in different ways. Economic valuation frameworks have emphasized the need to distinguish $\mathrm{ES}$, considered as 'ecological in nature' (Boyd \& Banzhaf 2007), from 'benefits', which may also derive from non- ecological inputs such as built capital or labour (Fisher \& Turner 2008; Balmford et al. 2011; Bateman et al. 2011). As benefits represent the actual improvement of a human's wellbeing, they are the appropriate ultimate focus for poverty alleviation and thus need to be distinguished from $\mathrm{ES}$, as well as disaggregated. In a simplistic disaggregation of benefits accruing to different stakeholder groups from three coastal ES in East Africa (Fig. 3), marine resources are harvested for consumption within local communities (Fig. 3a), but also for national (Crona et al. 2010) and, in the case of sea cucumbers, global markets for eventual consumption by wealthy consumers in Asia (Marshall et al. 2001; Fig. 3b). In addition, the white sand beaches and colourful coral reefs attract international tourists to resort locations such as Mombasa and Zanzibar (Fig. 3c).

\section{Categorization of ES}

According to aggregate analysis, and the MA categories of ES, both directly consumed (Fig. 3a) and traded (Fig. 3b) seafood belong to the provisioning ES of 'food' that is produced by ecosystems and eaten by humans. However, even simplistic disaggregation of benefits highlights the different types of benefits of each to different groups, and how they provide very different contributions to the well-being of the coastal poor, either by nutrition, or by generating income. Similarly, an aggregated analysis using the MA categories would conceptualize tourism as a cultural ES (focusing on the final consumer of the ES, and the contribution to their wellbeing). But, for poor local communities, tourism is effectively a provisioning service for income and employment, allowing their material needs to be met (Fig. 3c).

The MA categories of provisioning, regulating, cultural and supporting ES have been both critiqued (Boyd \& Banzaf 2007; 
Wallace 2007) and adapted for different purposes (Fisher $\&$ Turner 2009), but remain the default way of categorizing $\mathrm{ES}$ in the literature. For poverty alleviation, the categories are problematic because they group together ES that have entirely different functional relationships with poverty. The lack of disaggregation between beneficiaries obscures the different roles of those who capture, trade or finally consume each $\mathrm{ES}$, and how these processes contribute to the well-being of each. As Fisher and Turner (2008, p. 1169) point out, '[s]ervices are often a function of beneficiary's perspective' and, in the same way, appropriate categorization of services varies from one beneficiary to another. A poverty alleviation approach therefore must disaggregate ES beneficiaries so that $\mathrm{ES}$ can be analysed according to the benefits they provide to the poor.

\section{Cash and income as crucial indirect ES benefits for poverty alleviation}

Cash income and employment have important roles as mechanisms for ES to contribute to poverty alleviation (Fig. 3b, c). While rural communities may directly benefit from $\mathrm{ES}$, for example through the use of provisioning services such as mangrove for building materials and marine animals used for food (see Fig. 3a), income and employment are also key benefits (Fig. 3b,c). Focus groups conducted by Brown et al. (2008) with poor coastal stakeholders from five East African and south-east Asian countries emphasized the importance of cash and employment. Groups were prompted to describe all coastal and marine ES that they perceived, by open-ended questioning about how the sea/coastal area (and the animals and plants there) was important to them or their community. The resultant list of benefits were then scored for importance in a ranking exercise, and all focus groups identified either cash and employment, or processes generating earning possibilities (such as tourism attractions or fisheries) as the most important benefits from coastal ecosystems (Brown et al. 2008).

The importance of cash-based livelihoods in the linkage between poverty and $\mathrm{ES}$ is likely to increase as markets penetrate into rural areas (Pendleton \& Howe 2002; Godoy et al. 2005), particularly in the coastal zone (see Crona et al. 2010). As ES are commoditized (as exemplified by PES), they create opportunities for earning cash from ESs. Meanwhile, increasing availability of marketed goods in rural communities has also increased the importance of cash and employment as a means to improve well-being through the purchase of imported goods, healthcare, travel and education opportunities for children. In the remote Lau islands of Fiji, market penetration has radically affected people's relationship with local ecosystems. Communities who used to be dependent on local reef fisheries for food began to trade based on their cultural services (in terms of producing ceremonial kava bowls for export). As cash and marketed goods became available, they increasingly consumed imported rather than locally-caught fish (Turner et al. 2007).
Direct benefits from ES may be more important in terms of poverty prevention, for example through the provision of subsistence food, shelter and natural disaster mitigation. However, market mechanisms will be increasingly crucial for ES to contribute to poverty reduction, where cashearning opportunities from nature-based enterprises offer the best opportunity for reduction of rural poverty (WRI et al. 2008), particularly with the development of PES. The commoditization of nature this implies, which is also inherent in $\mathrm{ES}$ approaches, has received critique both from the perspective of the intrinsic value of nature (McCauley 2006) and from the perspective of capitalist appropriation of open access resources (Kosoy \& Corbera 2010). Meanwhile, the incorporation of the rural poor into industry or markets may also have negative impacts on well-being (Godoy et al. 2005). Regardless of the desirability of such changes, the reality of market integration demands that cash and employment be explicitly accounted for in any ES framework aimed at poverty alleviation.

Although cash and employment are clearly an (perhaps the most) important mechanism for poverty alleviation, much of the ES literature has surprisingly little emphasis on these. The MA synthesis, for example, despite its broad 'benefits' definition and emphasis on 'human well-being and poverty alleviation' (MA 2005), mentions 'income', 'employment' and 'livelihood' as ES benefits far less (17, 11 and 5 times, respectively) than terms implying direct benefits from services such as 'food', 'recreation', 'spiritual' and 'wood' (138, 41, 38 and 29 mentions).

Meanwhile, although ES valuation (Fisher \& Turner 2008) and accounting (Boyd \& Banzhaf 2007) frameworks emphasize the need to distinguish benefits from ES, they still place little or no emphasis on cash or employment when discussing benefits. Fisher and Turner (2008, p. 1168) referred to '. . . more food, better hiking, less flooding', while Balmford et al. (2011, p. 165) did not include income or employment in their preliminary list of $33 \mathrm{ES}$ benefits. This exclusion is logically sound when calculating aggregate values or national green accounts (see comparisons with GDP accounting in Boyd \& Banzhaf 2007), but such exercises are not designed to highlight poverty alleviation and suffer similar shortcomings for measurement of poverty alleviation as GDP (see Ravallion 2001).

More disaggregated analysis would lead to more emphasis on cash and employment. When human well-being is aggregated, the focus of analysis is the net contribution of benefits from ecosystems to humankind, therefore ignoring the exchange mechanisms that operate between different humans (such as trade) that are so important for poverty alleviation. A disaggregated perspective throws more focus on the importance of trade and the essential difference between direct use of ES, and their indirect importance for cash and employment (compare Fig. $1 a$ with Fig. $2 d$, and Fig. $3 a$ with Fig. $3 b$ ). The low emphasis on cash and employment in ES literature represents an implicit, and potentially incorrect, assumption that ES contribute to the well-being of the 
poor primarily through direct enjoyment of ES (for example through subsistence activities), when in fact ES may have greater impacts on the poor through indirect benefits (Figs $2 d$, $3 b, c)$.

\section{Practical implications of conceptual issues}

Beyond academic discussions, the conceptualization and categorization of ES have implications for how ES concepts are applied in practice (Wallace 2007). This can be illustrated by a simple example of valuation methods as they are applied to coastal ES, and how they reflect contributions to the wellbeing of the poor. Ecosystem goods are frequently valued based on adjusted market prices (Bateman et al. 2011), but the contribution of this ES to poverty alleviation requires knowledge of the different beneficiaries (for example the final consumer, people who derive an income through trade or exchange) and how the ES contributes to the overall wellbeing of each.

If ES are directly consumed by the poor (Fig. 3a), market prices, reflecting the willingness to pay of the consumers (if corrected with equity weights for limited purchasing power), would provide an indication of the importance of that service to the poor. In contrast, resource economists often call for the calculation of producer surplus (or economic rent) to guide management of fisheries towards rent-maximization, based on concepts of 'maximum economic yield'. This aggregate conceptualization of the benefits of fisheries may undervalue and ultimately undermine the contribution of small-scale fisheries to poverty alleviation in developing countries (Béné et al. 2010). Such issues are generated by a lack of emphasis on who benefits from the ES, and whether it is important for the poor primarily through nutrition (Fig. $3 a$ ) or cash generation (Fig. 3b).

Meanwhile, poor groups benefit from coastal tourism, by 'selling' experiences to wealthy consumers (Fig. 3c), which calls for calculation of the producer surplus at the relevant stage of the marketing chain to reflect cash-earning opportunities for local people (also interpreted through equity weights to reflect the significance of these values relative to other earnings). However, consumer willingness to pay is often used to value tourism (for example through travelcost and contingent valuation methods). The relative wealth of tourists and high costs paid to 'consume' this cultural ES result in inflated tourism values that overshadow other locallyheld values (Hicks et al. 2009) and offer limited insight to the actual poverty alleviation potential of local tourism-related industry. Thus, gross misrepresentations of the well-being contribution of different ES, particularly for the poorest, can result from valuation attempts that are not based on disaggregated understanding of the beneficiaries who capture, trade and finally consume each ES.

In summary, ES approaches that aim to inform poverty alleviation need to focus on elucidating and analysing benefits (namely the point at which ES improve the well-being of specific groups of humans) and how these can be maintained and maximized sustainably. This requires a disaggregated analysis that recognizes the different groups who benefit from each ES, the access mechanisms determining who benefits, and the individual contexts and aspirations determining how well-being is improved by ES. For the purposes of poverty alleviation, most ES research is still too focused on aggregate ES without fully understanding the distribution and nature of well-being benefits.

\section{APPLYING A DISAGGREGATED ANALYSIS}

This paper has highlighted four issues associated with aggregation of ES benefits and beneficiaries, which may limit the relevance of ES concepts and research for addressing poverty alleviation. In this section, we make some preliminary suggestions of how and when disaggregated analysis might be applied to understand ES and poverty alleviation.

Given the unequal, and often highly-skewed distribution of resources and access to their benefits in developing countries, it is evident that researchers must analyse ES benefits to the poor separately from the rest (or whole) of society. However, there are serious practical challenges in doing this. Disaggregation to increasingly smaller subgroups may provide increasingly accurate information on well-being benefits to key poor stakeholders, but is limited by the availability of disaggregated data, both on the access to and usage of ES, and of the situation, needs, financial assets and aspirations of beneficiaries. The data challenge is exacerbated by limited information on the flows and distribution of benefits from a wide range of non-marketed and intangible ES.

When, then, is it necessary to disaggregate, and what degree of disaggregation is necessary? We suggest that the greater the inequality within a system, the more fundamental are the issues around the unequal distribution of benefits and the marginal utility of income, and thus there is a greater need to disaggregate and account for this. Thus, work in developed countries (see Nelson et al. 2009; Bateman et al. 2011; Polasky et al. 2010) arguably has less serious distributional implications for poverty than work in developing countries. Unfortunately, precisely those systems where disaggregation is important are likely to be most limited in terms of available data. Disaggregation may not always be desirable, for example when developing green national accounting systems, which require objective aggregate metrics (Boyd \& Banzaff 2007) that cannot incorporate 'well-being contexts' and aspirations of individuals.

Secondly, which groups and social divisions should form the basis of disaggregated analysis? We suggest two approaches, exploratory or targeted disaggregation. In the former, groupings can be analysed based on ethnicity, gender, age, geographical location (as done by Hein et al. 2006) or specific groups compared to broader society (Polasky et al. 2010) dependent on data availability, to test the hypothesis of unequal benefits from ES. Disaggregation based on income or, where available, other indicators of wealth (such as material 
style of life; Cinner et al. 2009), is an obvious starting point to determine the specific impacts of ES interventions on the poor.

Targeted approaches would aim to identify appropriate groups for disaggregation by examining access mechanisms for specific ES and livelihood profiles, perhaps using grounded ethno-ecological research. This may identify appropriate groupings for disaggregation that cannot be perceived from larger-scale analysis.

Third, how to conduct disaggregated analysis to better understand linkages to poverty? Existing approaches can be adapted to improve their relevance to poverty alleviation. Modelling and mapping of ES trade-offs (see Nelson $e t$ al. 2009) can be coupled with stakeholder analysis to identify resulting distributional impacts. Where income data of beneficiaries are available, financial benefits from ES can be put into individual context, by applying the rarely-used tool of equity weights to $\mathrm{ES}$ costs and benefits (Bateman et al. 2011).

\section{CONCLUSIONS}

We have discussed the relevance of the ES approach to poverty alleviation and highlighted four issues that we perceive in the current thinking around ES and human well-being, particularly related to the aggregation of human well-being. The focus of ES as 'the benefits people derive from ecosystems' (MA 2005) remains a powerful conceptual lens with which to understand environment-development conflicts, but only if benefits are sufficiently disaggregated to analyse benefits to the poor. PES, as one mechanism to account for unequal distribution of costs and benefits of ES across society, requires such a disaggregated lens. While ES research following the MA has advanced understanding of trade-offs between ES, sufficient attention has yet to be focused on the resultant unequal impacts on the well-being of different individual humans. To address poverty alleviation, and support equitable PES, ES-based frameworks need to:

1. Explicitly disaggregate ES beneficiaries into poor and other vulnerable groups (for example by gender, class, ethnicity, geography, livelihoods and socioeconomic status).

2. Emphasize institutions and capabilities that determine the poor's access to ES.

3. Recognize the different well-being contribution of ES to different stakeholders (such as accounting for marginal utility of income), rather than aggregating total values of ES.

4. Explicitly focus on the benefits resulting (and distinct) from ES, as the point at which humans' well-being is enhanced. These may be derived jointly from ES and other (non-ecosystem related) goods and services, and include distributional mechanisms within society (such as markets, employment or cash).

For the ES concept to address the MA's stated scope of wellbeing and poverty alleviation, ES research needs to focus more on which humans are deriving benefits from $\mathrm{ES}$, and how this contributes to their well-being.

\section{ACKNOWLEDGEMENTS}

This work was supported by ESRC/NERCESPA (Ecosystem Services and Poverty Alleviation) situation assessment and we are grateful for stimulating discussions with partners. Bruce Lankford, Tim McClanahan, Marta Berbés-Blázquez, Beatrice Crona and two anonymous reviewers provided comments on the manuscript. Rozi Goodbody assisted with literature and manuscript preparation.

\section{References}

Adams, W.M., Aveling, R., Brockington, D., Dickson, B., Elliott, J., Hutton, J., Roe, D., Vira, B. \& Wolmer, W. (2004) Biodiversity conservation and the eradication of poverty. Science 306: 11461149.

Adger, W.N., Hughes, T.P., Folke, C., Carpenter, S.R. \& Rockstrom, J. (2005) Social-ecological resilience to coastal disasters. Science 309: 1036.

Alkire, S. (2002) Dimensions of human development. World Development 30: 181-205.

Baer, P. (2009) Equity in climate-economy scenarios: the importance of subnational income distribution. Environmental Research Letters 4: 015007.

Balmford, A., Fisher, B., Green, R.E., Naidoo, R., Strassburg, B., Kerry Turner, R. \& Rodrigues, A.S.L. (2011) Bringing ecosystem services into the real world: an operational framework for assessing the economic consequences of losing wild nature. Environmental Resource Economics 48: 161-175.

Bateman, I.J., Mace, G.M., Fezzi, C., Atkinson, G. \& Turner, K. (2011) Economic analysis for ecosystem service assessments. Environmental Resource Economics 48: 177-218.

Béné, C., Hersoug, B. \& Allison, E.H. (2010) Not by rent alone: analysing the pro-poor functions of small-scale fisheries in developing countries. Development Policy Review 28: 325-358.

Brown, K., Daw, T., Rosendo, S., Bunce, M. \& Cherrett, N. (2008) Ecosystem services for poverty alleviation: marine and coastal situational analysis. Synthesis report. Natural Environment Research Council (NERC)/Department for International Development (DFID), UK.

Boyd, J. \& Banzhaf, S. (2007) What are ecosystem services? The need for standardized environmental accounting units. Ecological Economics 63: 616-626.

Butler, C. \& Oluoch-Kosura, W. (2006) Linking future ecosystem services and future human well-being. Ecology and Society 11: 30.

Bulte, E.H., Lipper, L., Stringer, R. \& Zilberman, D. (2008) Payments for ecosystem services and poverty reduction: concepts, issues, and empirical perspectives. Environment and Development Economics 13: 245-254.

Carpenter, S.R., Mooney, H.A., Agard, J., Capistrano, D., DeFries, R.S., Díaz, S., Dietz, T., Duraiappah, A.K., Oteng-Yeboah, A., Pereira, H.M., Perrings, C. Reid, W.V., Sarukhan, J., Scholes, R.J. \& Whyte, A. (2009) Science for managing ecosystem services: beyond the Millennium Ecosystem Assessment. Proceedings of the National Academy of Science USA 106: 1305-1312. 
Cheung, W.W.L. \& Sumaila, U.R. (2008) Trade-offs between conservation and socio-economic objectives in managing a tropical marine ecosystem. Ecological Economics 66: 193-210.

Cinner, J.E., Daw, T. \& McClanahan, T.R. (2009) Socioeconomic factors that affect artisanal fishers' readiness to exit a declining fishery. Conservation Biology 23: 124-130.

Crona, B., Nyström, M., Folke, C. \& Jiddawi, N. (2010) Middlemen, a critical social-ecological link in coastal communities of Kenya and Zanzibar. Marine Policy 34: 761-771.

Daily, G.C., ed. (1997). Nature's Services: Societal Dependence on Natural Ecosystems. Washington, DC, USA: Island Press.

Dasgupta, P. (2001) Human Well-being and the Natural Environment. Oxford, UK: Oxford University Press.

Dietz, T., Rosa, E. \& York, R. (2009) Environmentally efficient wellbeing: rethinking sustainability as the relationship between human wellbeing and environmental impacts. Human Ecology Reviem 16: 114-123.

FAO (2007) The State of Food and Agriculture 2007. Rome, Italy: FAO.

Fisher, B. \& Turner, R.K. (2008) Ecosystem services: classification for valuation. Biological Conservation 141: 1167-1169.

Fisher, B., Turner, R.K. \& Morling, P. (2009) Defining and classifying ecosystem services for decision making. Ecological Economics 68: 643-653.

Godoy, R., Reyes-Garcia, V., Byron, E., Leonard, W.R. \& Vadez, V. (2005) The effect of market economies on the well-being of indigenous peoples and on their use of renewable natural resources. Annual Reviem of Anthropology 34: 121-138.

Hein, L., van Koppen, K., de Groot, R.S. \& van Ierland, E.C. (2006) Spatial scales, stakeholders and the valuation of ecosystem services. Ecological Economics 57: 209-228.

Hicks, C.C., McClanahan, T.R., Cinner, J.E. \& Hills, J.M. (2009) Trade-offs in values assigned to ecological goods and services associated with different coral reef management strategies. Ecology and Society 14(1):10 [www document]. URL http://www.ecologyandsociety.org/vol14/iss1/art10/

Johansson-Stenman, O. (2005) Distributional weights in cost-benefit analysis. Should we forget about them? Land Economics 81: 337352.

Kosoy, N. \& Corbera, E. (2010) Payments for ecosystem services as commodity fetishism. Ecological Economics 69: 1228-1236.

Landell-Mills, N. \& Porras, I.T. (2002) Silver Bullet or Fools' Gold? A Global Reviem of Markets for Forest Environmental Services and Their Impact on the Poor. London, UK: International Institute for Environmental Development.

MA (2003) Ecosystems and Human Well-being: A Framemork for Assessment. Washington, DC, USA: Island Press.

MA (2005) Ecosystems and Human Well-being: Synthesis. Washington, DC, USA: Island Press.

Marshall, N., Milledge, S.A.H. \& Afonso, P.S. (2001) Stormy seas for marine invertebrates; trade in sea cucumbers, seashells and lobsters in Kenya, Tanzania and Mozambique. TRAFFIC East/Southern Africa, Harare, Zimbabwe.

Matsue, N. (2009) Gender, trade and development in Kenya's marine fishery. MSc thesis, University of East Anglia, School of International Development, Norwich, UK.

McClanahan, T.R. \& Kaunda-Arara, B. (1996) Fishery recovery in a coral-reef marine park and its effect on the adjacent fishery. Conservation Biology 10: 1187-1199.

McCauley, D.J. (2006) Selling out on nature. Nature 443: 27-28.
Nelson, E., Mendoza, G., Regetz, J., Polasky, S., Tallis, H., Cameron, D., Chan, K.M., Daily, G.C., Goldstein, J., Kareiva, P.M., Lonsdorf, E., Naidoo, R., Ricketts, T.H. \& Shaw, M. (2009) Modeling multiple ecosystem services, biodiversity conservation, commodity production, and tradeoffs at landscape scales. Frontiers in Ecology and the Environment 7: 4-11.

Norgaard, R.B. (2010) Ecosystem services: from eye-opening metaphor to complexity blinder. Ecological Economics 69: 12191227.

Pagiola, S., Arcenas, A. \& Platais, G. (2005) Can payments for environmental services help reduce poverty? An exploration of the issues and the evidence to date from Latin America. World Development 33: 237-253.

Pearce, D. (2003) The social cost of carbon and its policy implications. Oxford Reviem of Economic Policy 19: 362-384.

Pendleton, L.H. \& Howe, E.L. (2002) Market Integration, Development, and Smallholder Forest Clearance. Land Economics 78: 1-19.

Perrings, C. (2006) Ecological economics after the Millennium Assessment. International Fournal of Ecological Economics and Statistics 6: 8-22.

Polasky, S., Nelson, E., Pennington, D. \& Johnson, K.A. (2010) The impact of land-use change on ecosystem services, biodiversity and returns to landowners: a case study in the state of Minnesota. Environmental and Resource Economics 48: 219-242.

Pollnac, R.B., Pomeroy, R.S. \& Harkes, I.H.T. (2001) Fishery policy and job satisfaction in three southeast Asian fisheries. Ocean and Coastal Management 44: 531-544.

Pollnac, R.B. \& Poggie, J.J. (2008) Happiness, well-being and psychocultural adaptation to the stresses associated with marine fishing. Human Ecology Reviem 15: 194-200.

Porter, M., Mwaipopo, R., Faustine, R. \& Mzuma, M. (2008) Globalization and women in coastal communities in Tanzania. Development 51: 193-198.

Raudsepp-Hearne, C., Peterson, G.D. \& Bennett, E.M. (2010a) Ecosystem service bundles for analyzing tradeoffs in diverse landscapes. Proceedings of the National Academy of Science USA 107: 5242-5247.

Raudsepp-Hearne, C., Peterson, G.D., Tengö, M., Bennett, E.M., Holland, T., Benessaiah, K., MacDonald, G.K. \& Pfeifer, L. (2010b) Untangling the environmentalist's paradox: why is human well-being increasing as ecosystem services degrade? BioScience 60: $576-589$.

Ravallion, M. (2001) Growth, inequality and poverty: looking beyond averages. World Development 29: 1803-1815.

Ribot, J.C. \& Peluso, N.L. (2003) A theory of access. Rural Sociology 68: 153-181.

Rodriguez, J.P., Beard Jr, T.D., Bennett, E.M., Cumming, G.S., Cork, S., Agard, J., Dobson, A.P. \& Peterson, G.D. (2006) Tradeoffs across space, time, and ecosystem services. Ecology and Society 11: 28 .

Ronnback, P., Crona, B. \& Ingwall, L. (2007) The return of ecosystem goods and services in replanted mangrove forests: perspectives from local communities in Kenya. Environmental Conservation 34: 313-324.

Srinivasan, U.T., Carey, S.P., Hallstein, E., Higgins, P.A.T., Kerr, A.C., Koteen, L.E., Smith, A.B., Watson, W., Harte, J. \& Norgaard, R.B. (2008) The debt of nations and the distribution of ecological impacts from human activities. Proceedings of the National Academy of Science USA 105: 1768-1773. 
TEEB (2010) The Economics of Ecosystems and Biodiversity: Mainstreaming the Economics of Nature: A Synthesis of the Approach, Conclusions and Recommendations of TEEB, Malta: Progress Press.

Turner, R.A., Cakacaka, A., Graham, N.A.J., Polunin, N.V.C., Pratchett, M.S., Stead, S.M. \& Wilson, S.K. (2007) Declining reliance on marine resources in remote South Pacific societies: ecological versus socio-economic drivers. Coral Reefs 26: 997 1008.

Wallace, K.J. (2007) Classification of ecosystem services: problems and solutions. Biological Conservation 139: 235-246.

WRI (2007) Nature's Benefits in Kenya: An Atlas of Ecosystem Services and Human Wellbeing. Washington, DC, USA and Nairobi, Kenya: Department of Resource Surveys and Remote Sensing, MENR, Central Bureau of Statistics and International Livestock Research Institute, WRI.
WRI, United Nations Development Programme, United Nations Environment Programme \& World Bank (2008) A Guide to World Resources 2008: Roots of Resilience-Groming the Wealth of the Poor. Washington, DC, USA: World Resources Institute.

Wunder, S. (2008) Payments for environmental services and the poor: concepts and preliminary evidence. Environment and Development Economics 13: 279-297.

Wunder, S., Engel, S. \& Pagiola, S. (2008) Taking stock: a comparative analysis of payments for environmental services programs in developed and developing countries. Ecological Economics 65: 834-852.

Zilberman, D., Lipper, L. \& McCarthy, N. (2008) When could payments for environmental services benefit the poor? Environment and Development Economics 13: 255-278. 